\title{
Neurological Involvement in COVID-19 Patients: A Narrative Review
}

\author{
Ramakant Yadav ${ }^{1}$ Dhiraj Kumar Srivastava ${ }^{2}$ Prashant Kumar Bajpai ${ }^{2}$ Raj Kumar ${ }^{3}$ \\ ${ }^{1}$ Department of Neurology, UP University of Medical Sciences, \\ Saifai, Etawah, Uttar Pradesh, India \\ ${ }^{2}$ Department of Community Medicine, UP University of Medical \\ Sciences, Saifai, Etawah, Uttar Pradesh, India \\ ${ }^{3}$ Department of Neurosurgery, UP University of Medical Sciences,

\begin{abstract}
Address for correspondence Ramakant Yadav, DM, Department of Neurology, UP University of Medical Sciences, Saifai, Etawah 206130, Uttar Pradesh, India (e-mail: rkyadav_2003@yahoo.com).
\end{abstract} Saifai, Etawah, Uttar Pradesh, India

J Neurosci Rural Pract 2020;11:526-529

\begin{abstract}
Background Coronavirus disease 2019 (COVID-19) is a viral disease caused by severe acute respiratory syndrome coronavirus 2 (SARS-CoV-2) belonging to the coronavirus family. The primary target of SARS-CoV-2 is peripheral mucosal cells of respiratory tract. Recent days have seen few cases where virus has affected extrapulmonary organ such as nervous system.

Materials and Methods The present study was a narrative review done using techniques of systemic review, that is, Preferred Reporting Items for Systematic Reviews and Meta-Analyses (PRISMA) guidelines. Electronic databases such as PubMed (Medline) and Google Scholar were searched systematically for published article from December 1, 2019 to June 5, 2020. A total of 189 articles were initially selected by the authors. A final list of 17 articles was prepared and following information were extracted from selected studies: study design, main result, and limitations of the study.

Results Majority of these article were descriptive studies describing spectrum of signs and symptoms among admitted patients. In majority of these studies, patients have developed symptoms suggestive of neurological involvement. Most common central nervous system symptoms reported were headache, followed by dizziness and

\section{Keywords}

- coronavirus infections

- SARS-CoV-2

- neurological involvement and its manifestations confusion. Similarly, the most common peripheral nervous system involvement was loss of taste and smell.

Conclusion The present study concludes that there are enough evidences to prove that SARS-CoV-2 infection affects both central and peripheral nervous system. Various mechanisms are proposed to explain the pathophysiology of neurological manifestations in COVID-19-positive patients that needs to be established and verified.
\end{abstract}

\section{Introduction}

Coronavirus disease 2019 (COVID-19) is a viral disease caused by severe acute respiratory syndrome coronavirus 2 (SARS-CoV-2) belonging to the coronavirus family. Coronaviruses are known to cause various self-limiting viral diseases, but recent years have seen few diseases that are known to cause severe respiratory syndrome and the latest addition to this is COVID-19.,
The primary target of SARS-CoV-2 is peripheral mucosal cells of respiratory tract. ${ }^{3}$ It is mostly invasive in nature with wide spectrum of diseases ranging from asymptomatic cases to severe acute respiratory distress syndrome.

However, recent days have seen few cases where virus has affected extrapulmonary organ such as nervous system..$^{3-9}$ One case of viral encephalitis with positive cerebrospinal fluid (CSF) for viral protein has been reported in China. ${ }^{10}$ It is 
also reported in few studies that patients also present with symptoms of anosmia and dysgeusia. ${ }^{11,12}$ Previous coronavirus pandemics such as SARS-CoV and Middle East respiratory syndrome (MERS) have clearly shown involvement of central and peripheral nervous system infections. These finding can also be clearly be applied on the present pandemic.

In the present study, we will discuss about the various mode/mechanism of coronavirus infection of central and peripheral system and the possible symptoms due to this infection. It also aims to determine the neurological involvement and its manifestations in COVID 19 patients.

\section{Materials and Methods}

The present study was a narrative review done to review the existing literature on SARS-CoV-2 and its involvement in central and peripheral nervous system. The articles were searched and retrieved using techniques of systemic review, that is, Preferred Reporting Items for Systemic Review and Meta-Analysis (PRISMA) guidelines. Electronic database such as PubMed (Medline) and Google Scholar were searched systematically for articles published from December 1, 2019 to June 5, 2020. Articles were searched using following keywords: "COVID-19" OR "CORONAVIRUS" OR "SARS-CoV-2" AND "NEUROLOGICAL MANIFESTATION."

Authors first searched abstract of the article using the above-mentioned keywords. Articles that were written in English and whose complete text was available were included in the final list.

A total of 189 articles were initially selected by the authors.

Out of 189 articles, 104 articles were removed on initial screening by the authors because their title does not match with the study objectives. In the second step, 32 articles were removed because they were review articles or opinion of different experts. Twelve articles were further removed because their main text was available in languages other than English. Furthermore, 11 more articles were removed from the main list because they were duplicate article. Thus, after second stage of screening, a total of 30 articles remained.

The authors looked for the complete text of the selected articles. Of the 30 articles selected in the second stage, 11 articles were further removed because their complete text could not be retrieved or unavailable for review.

Thus, a final list of 17 articles was prepared and following information were extracted from selected studies: study design, main result, and limitation of the study. Methodology section was also assessed by the authors.

\section{Results}

After an extensive literature search using a web-based search engines, a total of 189 article were suggested. Out of this, we prepared a list of 17 articles based on inclusion and exclusion criteria for review. Majority of these article were descriptive studies describing spectrum of signs and symptoms among admitted patients. ${ }^{3-12}$ Majority of these studies showed that patients may develop signs and symptoms suggestive of neurological involvement. Most common central nervous system
(CNS) symptoms reported were headache, followed by dizziness and confusion. Similarly, the most common sign of peripheral nervous system involvement was loss of taste and smell. ${ }^{12-15}$

One case of viral encephalitis with positive CSF for viral protein ${ }^{10}$ was also reported; however, one case series did not find out positive CSF in their patients. ${ }^{16,17}$ On case report presented two patients present with Miller-Fisher syndrome and polyneuritis cranialis. Similarly, one case report of myoclonic seizure was also reported in COVID-19-positive patient who had no respiratory symptom. ${ }^{18}$ However, none of the study is specifically designed to study the neurological symptoms in COVID-19 patients.

\section{Discussion}

It is noted in the present study that there is a scarcity of literature showing clear evidences of neurological manifestations in current COVID-19 pandemic. However, findings of previous coronavirus pandemics can also be safely applied on the current SARS-CoV-2 pandemic. In 2003, SARS-CoV epidemic, patients with neurological manifestation had their CSF positive for the virus.,19 In study of patients suffering for MERS, neurological manifestation was also reported in few patients..$^{20,21}$ So, it is quite imperative to presume that the current pandemic will also have patients presenting with different neurological manifestations. Some of these manifestations will be specifics such as cerebrovascular accidents, seizures, meningitis, and encephalitis, whereas majority will have nonspecific symptoms such as confusion, dizziness, headache, and myalgia. ${ }^{12-14}$

Most of the studies related to COVID-19 had few symptoms of CNS involvement such as headache, confusion, dizziness, ${ }^{12-15}$ and cerebrovascular accidents. ${ }^{6}$ Similarly, symptoms such as loss of taste and smell are suggestive of peripheral nervous system involvement.

\section{Mechanism for CNS Involvement}

Various mechanism has been proposed for the neuronal involvements such as direct infection injuries, hypoxic injuries, and immune mediated.

Direct injuries are mostly taking place through direct seeding of the virus into the neuronal tissue through blood circulation $^{22}$ or via olfactory nerve pathways. ${ }^{19}$ Direct seeding of the virus leads to viral encephalitis. Entry of virus through olfactory nerve is the most suggested pathway by different researchers. Mouse hepatitis virus model ${ }^{23}$ also supports this hypothesis. Virus migrates through sensory or motor neurons in both anterograde or retrograde directions through neuronal proteins, dynein, and kinesin. ${ }^{24}$ Entry of the virus through olfactory nerve pathway takes place in early phase of the infection. There are studies which indicate that patients present first with neurological symptoms are later found to be COVID-19 positive. $^{25}$

CNS involvement mostly takes place in the second week of the infection due to hypoxic injuries caused by the decrease oxygenation of blood. Due to decreased oxygen saturation in 
the blood, there is anerobic metabolism in the mitochondria of the brain cells leading to accumulation of the acid in the neuronal tissues, resulting in cerebral vasodilation, swelling of brain cells, interstitial edema, obstruction to blood flow leading to ischemia that result in headache and dizziness. ${ }^{26}$ In severe cases, there is a raised intracranial tension that results in drowsiness, bulbar conjunctival edema, and even coma. In patients who are prone to cerebrovascular accidents, hypoxia results in cerebral stroke via a release of cytokine storms that mostly happen in second week. This is mostly through immune mediation. ${ }^{27}$

Another mechanism is related to the CNS manifestation. Persistence of the virus in the neuronal tissue and their ability to infect macrophages, microglia, and astrocytes result in release of large quantities of proinflammatory cytokines such as interleukin-2 (IL-2), IL-5, IL-6, and tumor necrosis factor-alpha. These cytokines are important for the cytokine storms and are directly corelated with the severity of the infection. ${ }^{28}$

\section{Clinical Manifestations in COVID-19 Infection}

\section{Viral Encephalitis}

Most cases present with headache, fever, vomiting, and convulsions. Shi et $\mathrm{al}^{10}$ reported a case of viral encephalitis with positive CSF for viral protein. However, in a case report, two COVID-19-positive patients with neurological manifestations were reported. However, their CSF was not positive for the viral protein. This indicates that there is scope for future studies to confute or refute the presence of viral encephalitis due to COVID-19 infections.

\section{Acute Cerebrovascular Accidents}

Data from the various studies show that there is a release of large amounts of cytokines from glial cells leading to cytokine storm. ${ }^{28}$ Thus, patients with severe infection of SARS-CoV-2 infection are independent risk factors for the cerebrovascular accidents. Majority of these cerebrovascular accident are hemorrhagic/ischemic in nature. Elevated D dimer assay can be a guiding point for early identification of case which is at risk of developing signs of cerebrovascular accidents. ${ }^{29}$ Studies conducted on COVID-19-positive patients in New York reported that majority of the patients are dying due to stroke in their early adulthood. ${ }^{30}$

\section{Infectious Toxic Encephalopathy}

Infectious toxic encephalopathy results from systemic toxemia, metabolic derangement, or hypoxia developed during the process of disease progression. Patients during their early course may present with headache, dysphoria, and delirium. Seriously affected patients may develop loss of consciousness, coma, or paralysis. ${ }^{31-33}$ As the COVID-19-positive patients develop severe hypoxia during the course of the disease, they are prone to infectious toxic encephalopathy. ${ }^{27}$
This is further supported by the autopsy finding of COVID-19 patients that shows signs of cerebral edema in brain tissues. ${ }^{33}$

\section{Conclusion}

The present study concludes that there is a scarcity of good quality research that specifically focuses on neurological involvements in COVID-19 patients. Also, the present study concludes that there is enough evidence to prove that SARSCoV-2 infection affects neurological tissues both in central and peripheral nervous system. Various mechanisms are proposed to explain the pathophysiology of neurological manifestations in COVID-19-positive patients that need to be established and verified. This should be supplemented with biochemical and electrophysiological studies.

However, the present study also concludes that some patients, especially those with severe infection, may have clinical and subclinical neurological manifestation that can be assigned to impaired electrolyte and metabolic derangement. This should also be considered while evaluating patients with neurological manifestations.

\section{Funding \\ None.}

\section{Conflict of Interest}

None declared.

\section{References}

1 Rothan HA, Byrareddy SN. The epidemiology and pathogenesis of coronavirus disease (COVID-19) outbreak. J Autoimmun 2020;109:102433

2 Desforges M, Le Coupanec A, Dubeau P, et al. Human coronaviruses and other respiratory viruses: underestimated opportunistic pathogens of the central nervous system? Viruses 2019;12(1):E14

3 Huang C, Wang Y, Li X, et al. Clinical features of patients infected with 2019 novel coronavirus in Wuhan, China. Lancet 2020;395(10223):497-506

4 Mao L, Jin H, Wang M, et al. Neurologic manifestations of hospitalized patients with coronavirus disease 2019 in Wuhan, China. JAMA Neurol 2020;77(6):1-9

5 Helms J, Kremer S, Merdji H, et al. Neurologic features in severe SARS-CoV-2 infection. N Engl J Med 2020;382(23):2268-2270

6 LiY, Li M, Wang M, et al. Acute cerebrovascular disease following COVID-19: a single center, retrospective, observational study. Stroke Vasc Neurol 2020;svn-2020-000431

7 Wang D, Hu B, Hu C, et al. Clinical Characteristics of 138 hospitalized patients With 2019 novel coronavirus-infected pneumonia in Wuhan, China. JAMA 2020;323(11):1061-1069

8 Yang $\mathrm{X}, \mathrm{Yu} \mathrm{Y}, \mathrm{Xu} \mathrm{J}$, et al. Clinical course and outcomes of critically ill patients with SARS-CoV-2 pneumonia in Wuhan, China: a single-centered, retrospective, observational study. Lancet Respir Med 2020;8(5):475-481

9 Wu Y, Xu X, Yang L, Liu C, Yang C. Nervous system damage after COVID-19 infection: Presence or absence? Brain Behav Immun 2020;87:55 
10 Shi $\mathrm{H}$, Han X, Jiang N, et al. Radiological findings from 81 patients with COVID-19 pneumonia in Wuhan, China: a descriptive study. Lancet Infect Dis 2020;20(4):425-434

$11 \mathrm{Xu} \mathrm{XW}, \mathrm{Wu} \mathrm{XX}$, Jiang XG, et al. Clinical findings in a group of patients infected with the 2019 novel coronavirus (SARSCov-2) outside of Wuhan, China: retrospective case series. BMJ 2020;368:m606

12 Ye M, Ren Y, Lv T. Encephalitis as a clinical manifestation of COVID-19. Brain Behav Immun 2020;S0889-1591(20)30465-7

13 Toscano G, Palmerini F, Ravaglia S, et al. Guillain-Barré syndrome associated with SARS-CoV-2. N Engl J Med 2020;382(26):2574-2576

$14 \mathrm{Xu} \mathrm{H}$, Zhong L, Deng J, et al. High expression of ACE2 receptor of 2019-nCoV on the epithelial cells of oral mucosa. Int J Oral Sci 2020;12(1):8

15 Al Saiegh F, Ghosh R, Leibold A, et al. Status of SARS-CoV-2 in cerebrospinal fluid of patients with COVID-19 and stroke. J Neurol Neurosurg Psychiatry 2020;91(8):846-848

16 Gutiérrez-ortiz C, Méndez-guerrero A, Rodrigo-rey S, et al. Miller Fisher syndrome and polyneuritis cranialis in COVID19. Neurology 2020;95(5):e601-e605

17 Vollono C, Rollo E, Romozzi M, et al. Focal status epilepticus as unique clinical feature of COVID-19: A case report. Seizure 2020;78:109-112

18 Bohmwald K, Gálvez NMS, Ríos M, Kalergis AM. Neurologic alterations due to respiratory virus infections. Front Cell Neurosci 2018;12:386

19 State of Knowledge and Data Gaps of Middle East Respiratory Syndrome Coronavirus (MERS-CoV) in Humans. PLoS Curr 2013;5

20 Saad M, Omrani AS, Baig K, et al. Clinical aspects and outcomes of 70 patients with Middle East respiratory syndrome coronavirus infection: a single-center experience in Saudi Arabia. Int J Infect Dis 2014;29:301-306

21 Simanjuntak Y, Liang JJ, Lee YL, Lin YL.. Japanese encephalitis virus exploits dopamine D2 receptor-phospholipase $C$ to target dopaminergic human neuronal cells. Front Microbiol $2017 ; 8-651$
22 Bergmann CC, Lane TE, Stohlman SA. Coronavirus infection of the central nervous system: host-virus stand-off. Nat Rev Microbiol 2006;4(2):121-132

23 Swanson PA II, McGavern DB. Viral diseases of the central nervous system. Curr Opin Virol 2015;11:44-54

24 Hopkins C, Surda P, Whitehead E, Kumar BN. Early recovery following new onset anosmia during the COVID-19 pandemic - an observational cohort study. J Otolaryngol Head Neck Surg 2020;49(1):26

25 Abdennour L, Zeghal C, Dème M, Puybasset L. [Interaction brain-lungs]. Ann Fr Anesth Reanim 2012;31(6):e101-e107

26 Guo YR, Cao QD, Hong ZS, et al. The origin, transmission and clinical therapies on coronavirus disease 2019 (COVID-19) outbreak - an update on the status. Mil Med Res 2020;7(1):11

27 Jamilloux Y, Henry T, Belot A, et al. Should we stimulate or suppress immune responses in COVID-19? Cytokine and anti-cytokine interventions. Autoimmun Rev 2020;19(7):102567

28 Wang Y, Wang Y, Chen Y, Qin Q. Unique epidemiological and clinical features of the emerging 2019 novel coronavirus pneumonia (COVID-19) implicate special control measures. J Med Virol 2020;92(6):568-576

29 Young and middle-aged people, barely sick with covid-19, are dying of strokes. Available at: https://www.washingtonpost. com/health/2020/04/24/strokes-coronavirus-young-patients/. Accessed July 5, 2020

30 Mizuguchi M, Yamanouchi H, Ichiyama T, Shiomi M. Acute encephalopathy associated with influenza and other viral infections. Acta Neurol Scand 2007;115(4, Suppl):45-56

31 Tauber SC, Eiffert H, Brück W, Nau R. Septic encephalopathy and septic encephalitis. Expert Rev Anti Infect Ther 2017;15(2):121-132

32 Young GB. Encephalopathy of infection and systemic inflammation. J Clin Neurophysiol 2013;30(5):454-461

33 Xu Z, Shi L, Wang Y, et al. Pathological findings of COVID-19 associated with acute respiratory distress syndrome. Lancet Respir Med 2020;8(4):420-422 